\title{
Development of a Land Information System of Tumpure Residential and Commercial Layout in Akko Local Government Area of Gombe State
}

\author{
Pindiga, A. M. ${ }^{1}$. and Orisakwe, K. U. ${ }^{2}$ \\ 1. Department of Surveying and Geoinformatics Federal Polytechnic Bauchi, Bauchi State. \\ 2. Department of Surveying and Geoinformatics Modibbo Adama University of Technology Yola, Adamawa \\ State
}

\begin{abstract}
The study has to do with the method and steps in creation and development of a Land Information System (LIS) for Tumpure residential and commercial layout in Akko Local Government Area (LGA) of Gombe State. This involved the creation and testing a multimedia relational database of the attributes of the individual parcels which were linked to the polygonized spatial positions of the parcels in Geographic Information Systems $(G I S)$ in Arcview 3.2a software environment. The analogue layout plan of the area of study was acquired, scanned, Georeferenced and digitized in AutoCAD 2000i environment. The digitized layers were then exported into the Arcview 3.2a software for parcel polygonization and subsequent table creation and linkage to the graphics. Video clips and snap shots of buildings and other special features obtained from individual parcels were recorded with digital camera and linked to their respective parcels in the Arcview software. High resolution satellite imagery covering the layout was obtained from Google Earth, Georeferenced and overlaid with the parcel layer to reveal the features contained in each parcel pictorially. The structured information contained in the database was evaluated and tested and found to be easily and readily accessible and retrievable through locational and attribute queries. The results demonstrated the efficacy of the system. Adequate recommendations were also made.
\end{abstract}

Keywords: Cadastre, Multipurpose Cadastre, Database, parcel and integrated approach

\section{Introduction:}

Land is a platform of all forms of human activity. It is indeed the natural habitat of man. Its use is crucial for economic, social, political and environmental advancement of all countries of the world and indeed for human survival. Although, land is part of man's natural heritage but access to land is controlled by ownership patterns. This ownership of land or acquisition has not been without tenural problems. It is therefore partitioned for administrative and economic purposes and used and transformed in a number of ways. Population growth, technological and social hazard and environmental degradation have all to be taken into greater account today be administrators, resource planners, policy makers who make decisions about the land. Therefore, they need more detailed; organized, well-structured, digital land information has not been traditionally available (Dale and McLaughlin, 1988).

A Land Information System (LIS) is a computerized tool for legal, administrative and economic decision making. It is indeed an aid for planning and development and consists of a structured database with spatial referenced land related attribute and spatial data for a defined area and of procedures and techniques for the systematic collection, updating, processing and distribution of the data to provide solution to land management problems (Pindiga, 2012).

Tumpure residential and commercial layout (LP/GM/5) in Akko Local Government Area (LGA) in Gombe State is a relatively new layout design that was created in order to to accommodate the fast-growing population and demand for land both in the administrative and commercial centres of Gombe State.

\section{Area Of Study}

Tumpure (the study area) is a layout in Akko LGA of Gombe State, see figures 1, 2 and 3 below for details. It is about five (5) kilometres west of the city centre of Gombe metropolis. The land mass has an area of approximately 128 hectares and bounded by the following Universal Transverse Mercator (UTM) coordinates (Point 1)730811.61 E ; 1136284.60 N, Point 2 730811.61 E ; 1138485.12 N, Point 3 732626.54 E ; 1138485.12 $\mathrm{N}$ and Point 4 is $732626.54 \mathrm{E}, 1136284.60 \mathrm{~N}$. It is on relatively flat terrain surrounded by isolated hills. 


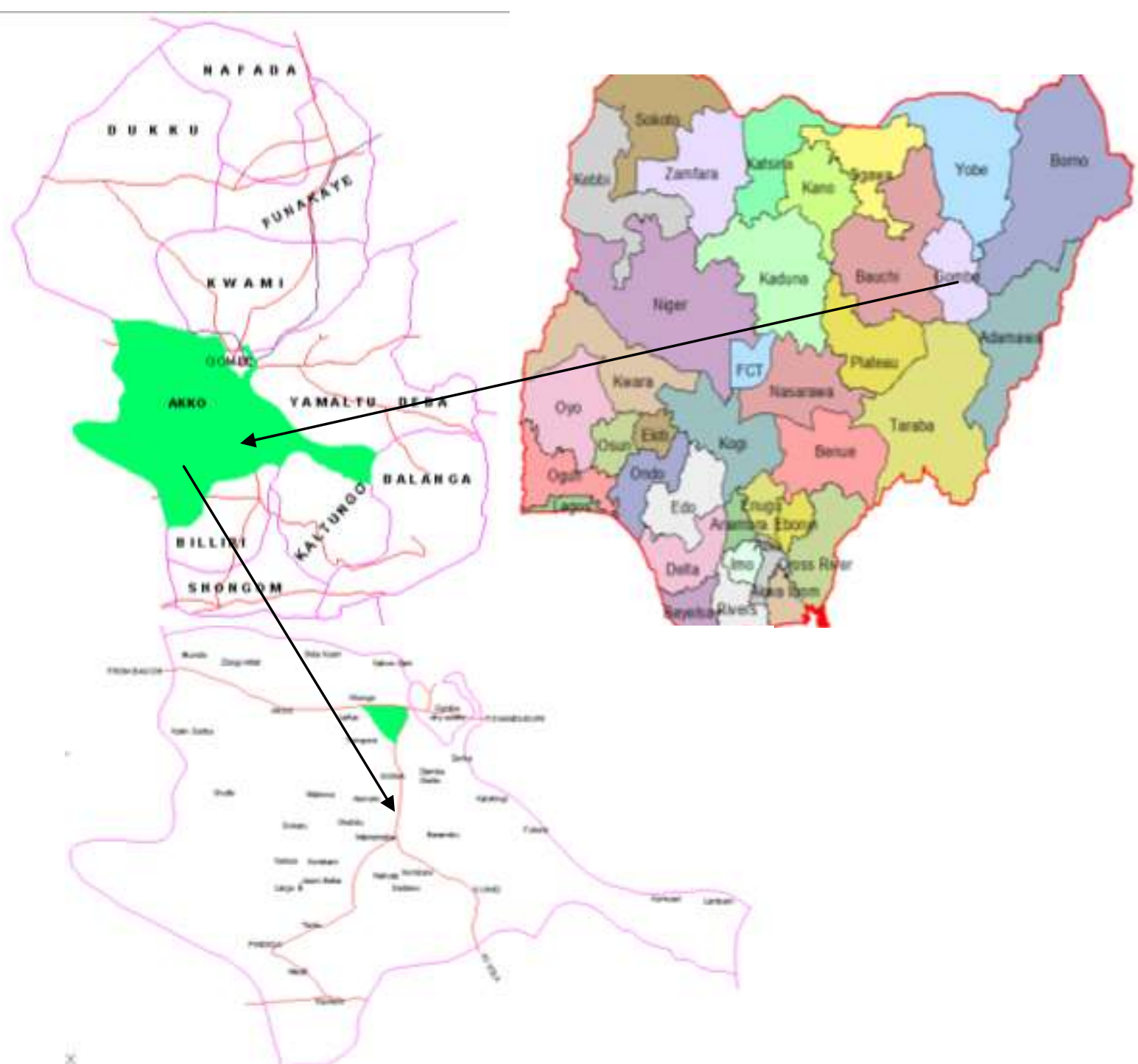

Gombe State Ministry of Lands and Survey which is responsible for keeping records of Land allottees as well as updating any eventual changes regarding land is observed to currently operate the manual/analogue method of acquiring, storing, processing, updating and presenting and keeping land-related information inform of paper files and paper maps and plans. Apart from the limited number of qualified staff, the analogue record keeping has increasingly become inefficient, cumbersome and slow in dealing with the issues of complexity and rapid increase in demand for land its records. This has undoubtedly led

(a) Double allocation of a single plot to two or more individuals.

(b) Overlapping of plots when charted on master sheets.

(c) Difficulty/Inconsistency in obtaining information about land

(d) Non-payment of rents due to lack of up-to-date information about the owner.

(e) Existence of more than one base map for plotting of new or processed applications.

(f) Poor land record keeping.

(g) Duplication of efforts.

That most states of the Nigerian Federation have gone digital in terms of Land and related record keeping and the establishment of robust multipurpose cadastral system, Gombe State cannot be an exception. Pindiga (2011) observed that the fuel driving the engine of growth and sustainable development of any state or nation is a reliable and up-to-date geoinformation.

The effective and efficient operation of a nation's cadastral system is an integral part of sustainable development. In recent years, cadastral systems have been influenced by the introduction of the geoinformation scene through the development of the multipurpose cadastre concept. The concept is expected to benefit all levels of government and society. Increased sharing of datasets, public transactions of data and reduction of administrative costs are a few of the benefits foreseen. Orisakwe (2011) observed that cadastre since inception has been a manually maintained and operated land records system that served a single purpose of revenue 
generation. Dale and McLaughlin (1988) advocated for the establishment and operation of a multi-purpose cadastre. Potdar (2010) identified three types of cadastre as:

(1) Tax Cadastre (2) Real Cadastre (3) Legal Cdastre

He further suggested a method of their integration through legislations as an act of law. Olaleye (1998) observed in Ezeigbo (1998) eds that complexities associated with modern land transactions need integrated approach and system. Ezeigbo et al (1998) further noted that population expansion and increased commercial activities are among the complexities of modern land administration which has made landuse become more intense and complex while competition for specific tracts of land and for resource use have escalated. There is therefore a need for a modern, complete and up-to-date database to support land conveyance procedures which will furnish a basis for equitable taxation and provides the much needed information for resource management and environmental planning. This need can only be sustained by a robust multi-dimensional multipurpose cadastre.

In setting up a cadastral information system, Adeoye (1996) outlined two main issues to be considered as:

(1) Spatial component/Survey data describing the spatial disposition of the parcels in

the real world cadastral maps.

(2) Non-spatial component describing details such as ownership details, tax valuables etc.

Adeoye (1996) used spatial database for the spatial components while Microstation Geographic for the nonspatial data. For customized query and report generation, the database was put in Oracle format. This approach earned him unlimited Cadastral Information System. A United States of American Committee in Geodesy in 1980 affirmed that conceptually a multipurpose cadastre is a framework of land records that supports continuous, readily available and comprehensive supply of up-to-date information associated with individual parcels of land. It is a multi-layer cadastre comprising (a) A Geodetic Reference framework (b) A base map (c) A Cadastral overlay (d) A unique identifying number assigned to each parcel $€$ A series of land data files and (f) A database Management system (DBMS) in which different types of data are overlaid and integrated to provide comprehensive, complete and integrated solution to land management problems.

The committee further asserted by identifying the key determinants of a multipurpose cadastre through the answers to the following questions:

* What is the status of the existing system?

* What are the objectives of the users of the system?

- What standards and procedures are required to meet the desired objectives of users?

* What are the costs and benefits?

This study bore in mind these questions in designing the LIS in Tumpure while having the technical components of the multipurpose cadastre adequately provided. Moha et al (2003) in their Moroccan experience said that only where these technical components are adequately provided can the multipurpose cadastre eventually be expanded to a multipurpose Land-data system incorporating natural resource base and land-related socioeconomic data. Moha et al (2003) went further to identify three different components of the multipurpose cadastre as:

$>$ The Juridical Cadastre

$>$ The National Cadastre

$>$ The National Land Registry

Jukka (2008) said that the main aim of multipurpose cadastre in Zanzibar was for poverty alleviation. This was also in line with the 7-point agenda of the Federal Government of Nigeria of which Land Reform was one. Therefore, to achieve the aim of establishing LIS for Tumpure the study set out with the following objectives:

- Collecting information on the buildings (condition, units, and photographs).

- Developing databases for revenue collection (rents, VAT, stamp duty etc).

- Developing databases for effective development control.

- Developing databases for conservation and maintenance of buildings.

- Developing further the already operational database for monitoring of utility management.

\section{Materials And Methods}

Developing a multipurpose cadastre involved the use of hardware, software and procedures in capturing, processing, analyzing, modelling and presenting geospatial data. Developing a multipurpose cadastre for Tumpure residential and commercial layout (LP/GM/5) in Akko Local Government Area of Gombe State was achieved through the conversion of the existing cadastral layout of the area. Satellite image of the area was also obtained and overlaid with the digitized parcel layer using a common reference coordinate system.

The attribute information was obtained through personal interviews, physical inspection and some were collected from the Ministry of Lands and Survey Gombe State. Also, as part of the attribute data, photographs and video shots were obtained of some of the existing structures in the area. These attribute data were used in creating a spatial database in a GIS implementation software called Arcview 3.2a. Analysis was performed on 
the database by raising several queries.

The normalization method of relational data structure was used whereby all the information in the database were represented in the form of tables or relations

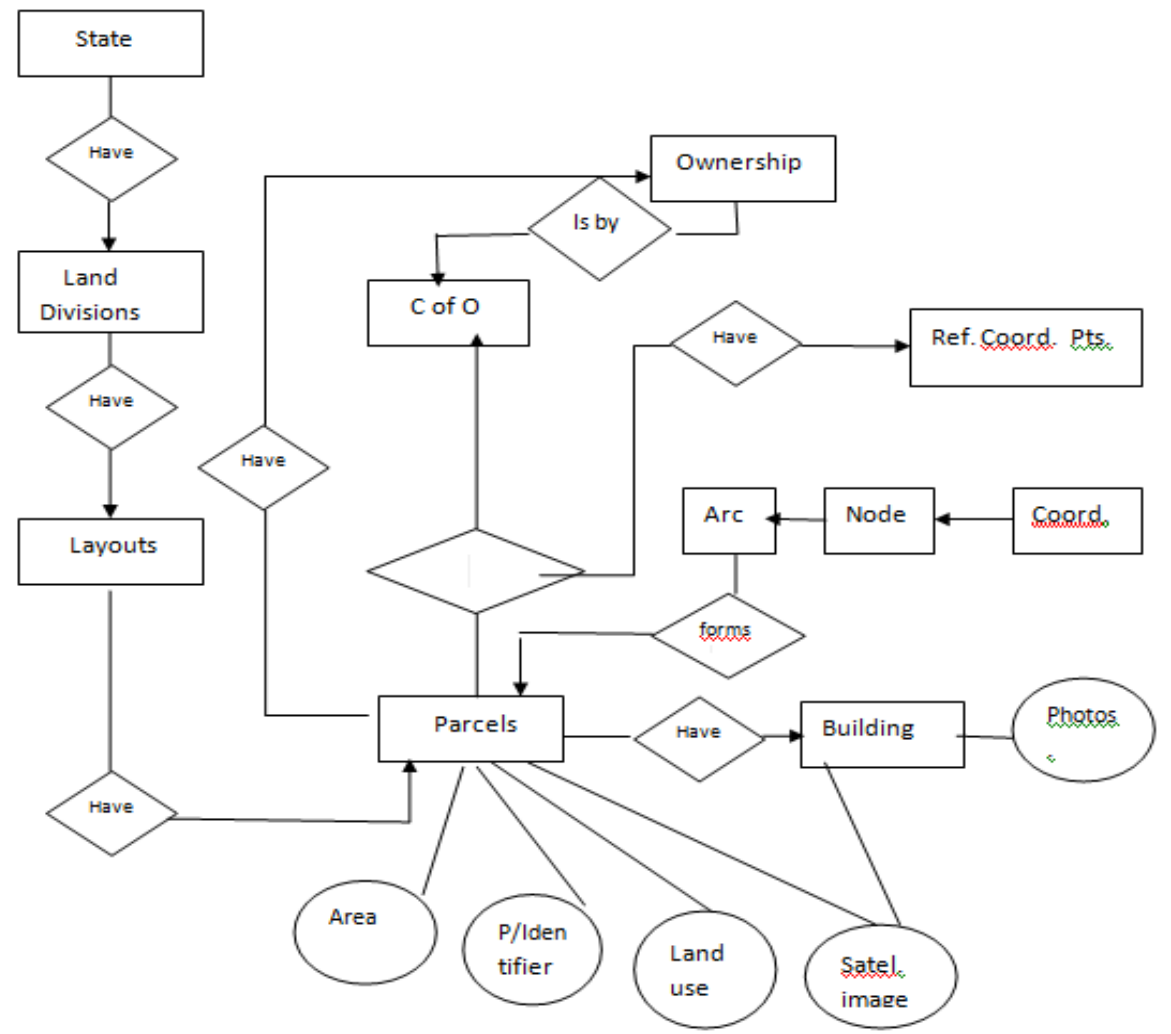

Fig. 2: Showing a Simple Entity Relationship Diagram of the Conceptual Database (Adapted from Odedare 2004)

Figure 2 above showed the entity relationship diagram used in this study whereby the following tables resulted:

TABLE 1: PARCEL TABLE

\begin{tabular}{|c|c|c|c|c|c|c|}
\hline PARCELID & USE & VALUE & AREA & PICTUREID & LOCATION & PLOT NO. \\
\hline 1 & Residential & 700,000 & 1285.54 & T01 & GDP/5 & RM 400 \\
\hline 2 & Commercial & $1,500,000$ & 1280.01 & T040 & GDP/5 & LH78 \\
\hline 3 & Residential & 500,000 & 1288.50 & T012 & GDP/5 & RM10 \\
\hline 4 & Vacant & Null & 1287.98 & T05 & GDP/5 & RM43 \\
\hline 5 & Residential & 650,000 & 1283.66 & T032 & GDP/5 & RM20 \\
\hline
\end{tabular}

TABLE 2: OWNER'S TABLE

\begin{tabular}{|l|l|l|l|l|l|l|}
\hline $\begin{array}{l}\text { OWNER } \\
\text { ID }\end{array}$ & ONAME & GENDER & $\begin{array}{l}\text { BIRTH } \\
\text { PLACE }\end{array}$ & OCCUPATION & STATE & LGA \\
\hline 1 & Bello Yayari & Male & Kashere & Business Man & Gombe & Dukku \\
\hline 2 & Zephaniah Shehu & Male & Billiri & Civil Servant & Gombe & Billiri \\
\hline 3 & Alh. Musa Haruna & Male & Tumu & Farmer & Gombe & Akko \\
\hline 4 & Muhd. Mahdi Muazu & Male & Deba & Civil Servant & Gombe & Y/Deba \\
\hline 5 & Dr. Adamu Alkali & Male & Kumo & Civil Servant & Gombe & Akko \\
\hline
\end{tabular}

TABLE 3: NODE TABLE

\begin{tabular}{|l|l|l|}
\hline NODE & Y-CO-ORDS. & X-CO-ORDS. \\
\hline GM 6421 & 1137065.21 & 731696.67 \\
\hline GM 6422 & 1137037.00 & 731691.12 \\
\hline GM6424 & 1137065.23 & 731667.60 \\
\hline GM6425 & 1136927.54 & 734586.21 \\
\hline
\end{tabular}


Development Of A Land Information System Of Tumpure Residential And Commercial Layout In Akko

TABLE .4: ARC TABLE

\begin{tabular}{|l|l|l|l|l|}
\hline ARC ID & BNODE & ENODE & LPAR & RPAR \\
\hline T1 & GM6422 & GM6421 & Road & LH 11 \\
\hline T2 & GM6421 & GM6425 & LH 9 & LH 11 \\
\hline T3 & GM6425 & GM6424 & LH 11 & LH 12 \\
\hline T4 & GM6424 & GM6422 & LH 11 & 1 LH 13 \\
\hline
\end{tabular}

This involves the various stages through which the acquired data will be process into spatial databases. The summarized graphical representation of the entire stages can be seen in the diagram of fig. (5).

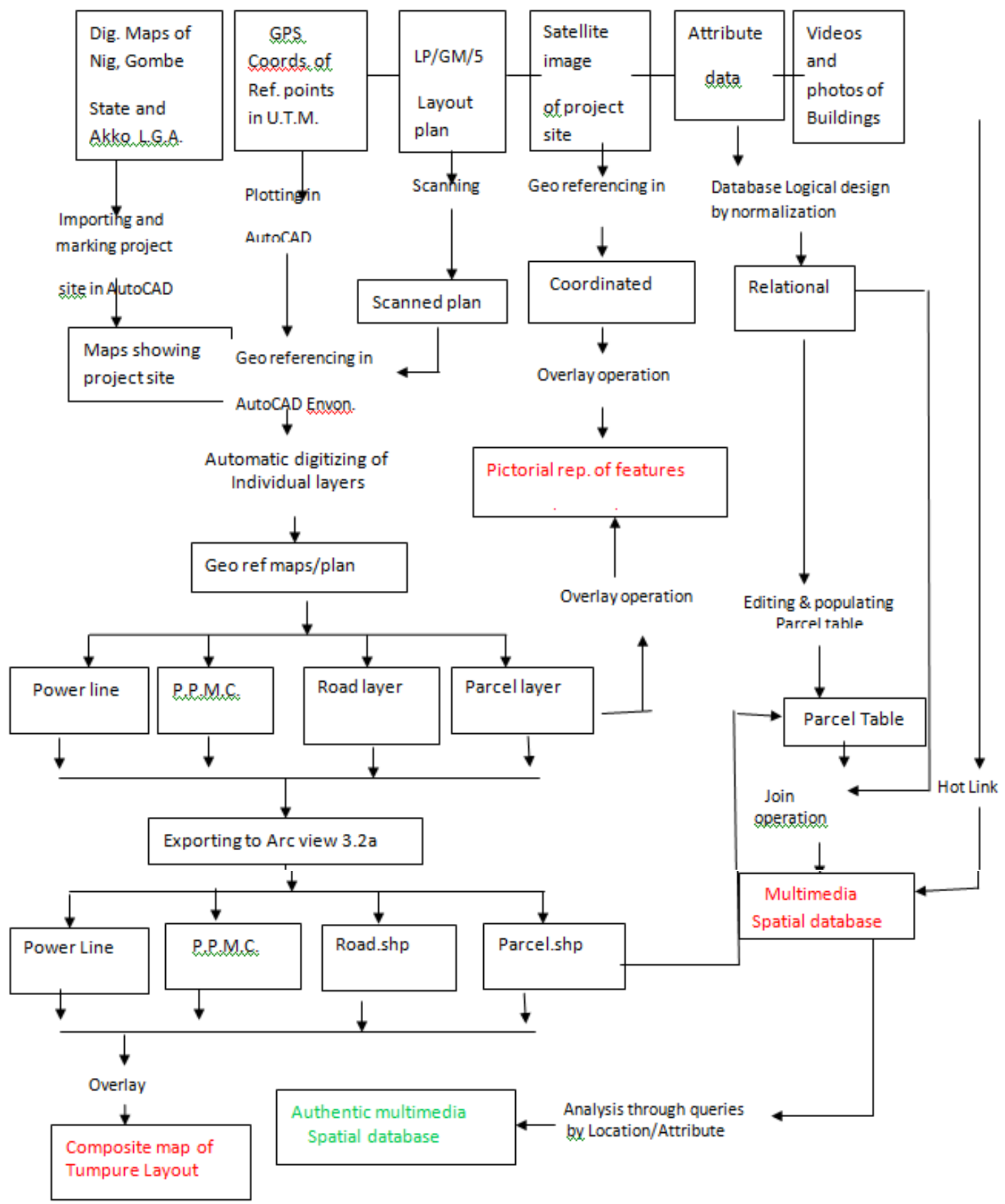

Fig.5: Showing Cartographic model of the project methodology 


\section{Results And Discussion}

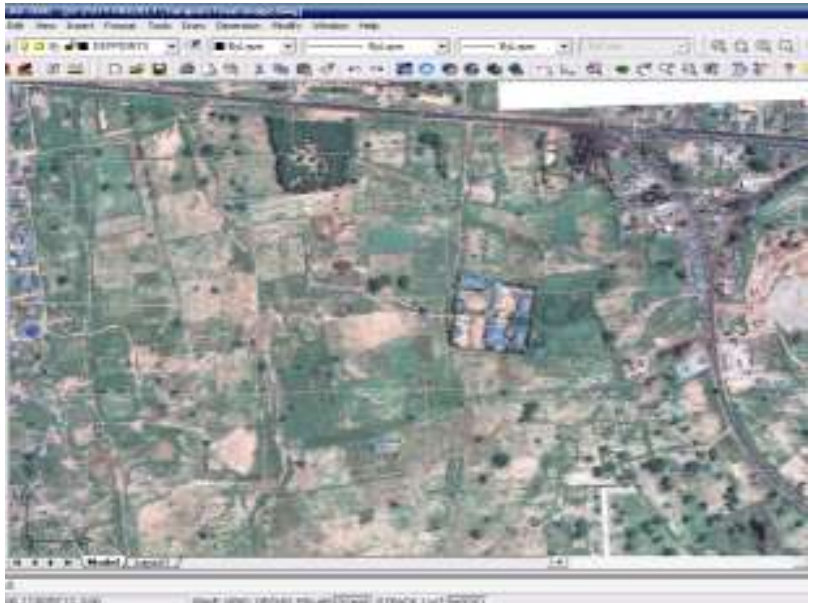

Fig 6 shows Georeferenced mosaic of 25 sets of satellite images covering the entire area of study. The first image was Georeferenced to the plotted referenced coordinates and thereafter subsequent images were referenced to the adjoining already Georeferenced images using common points between them.

Fig.6: Georeferenced satellite image showing Tumpure layout

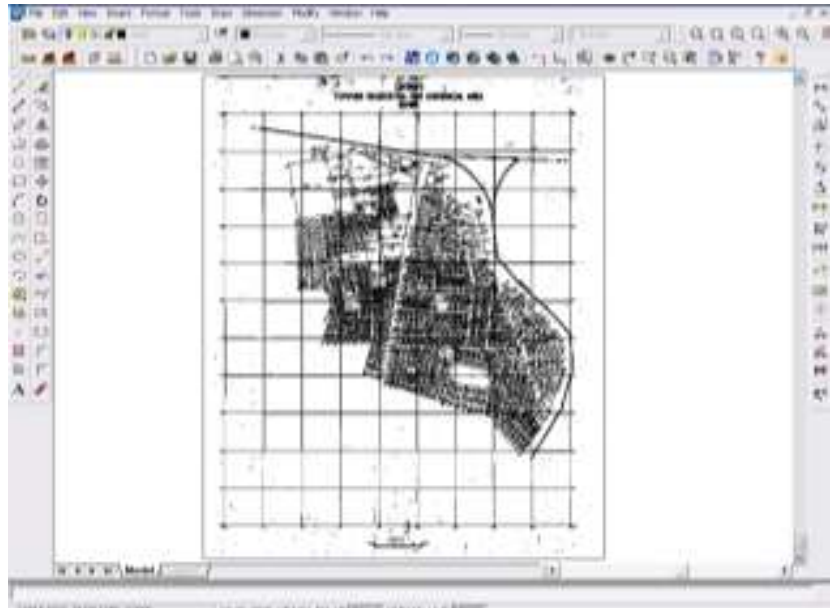

Fig 7 shows the scanned and Georeferenced analogue map of Tumpure done in AutoCAD environment.

Fig. 7: Scanned Plan of Tumpure Layout in AutoCAD environment.

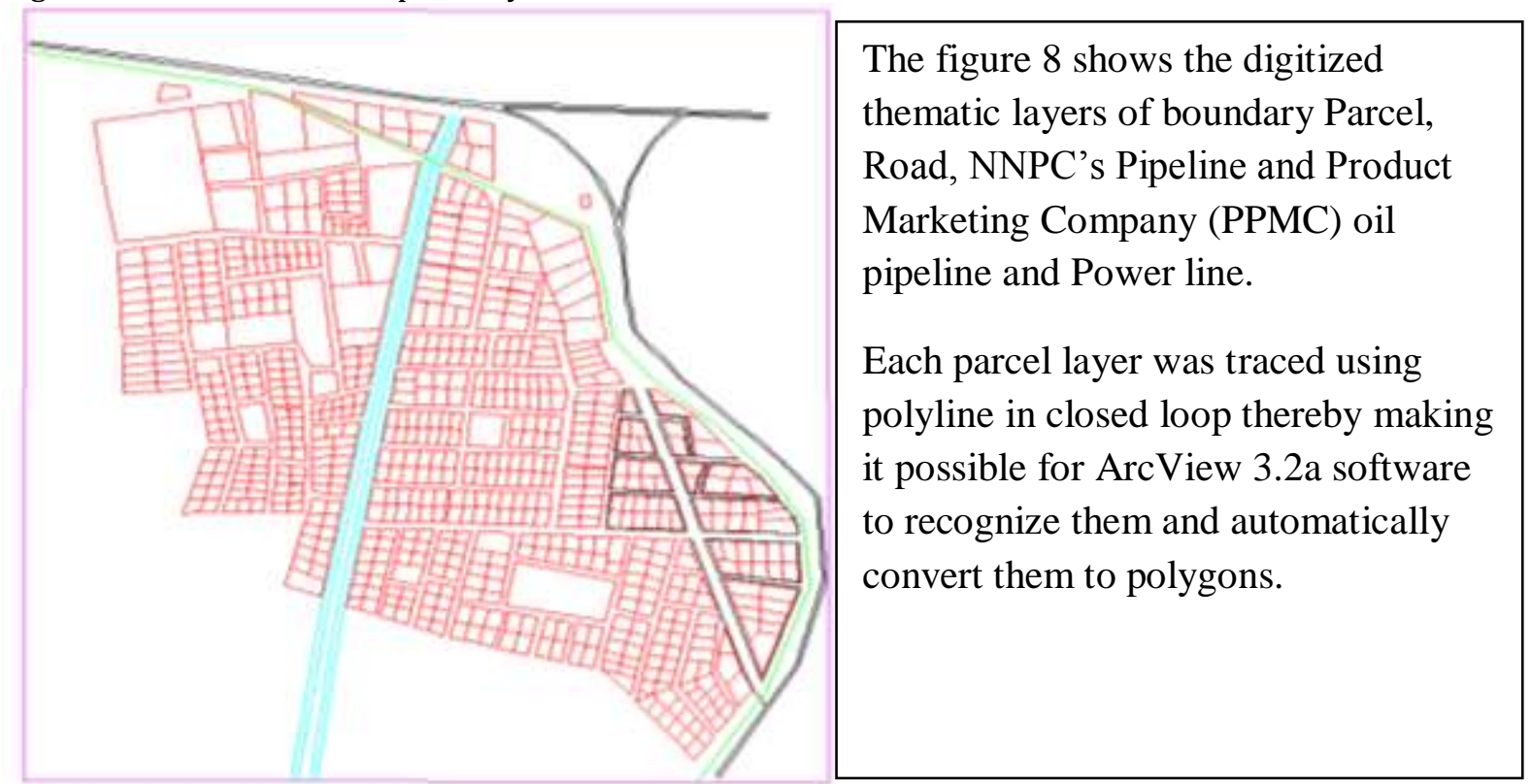

Fig. 8: Plan showing digitized features in their respective layers 


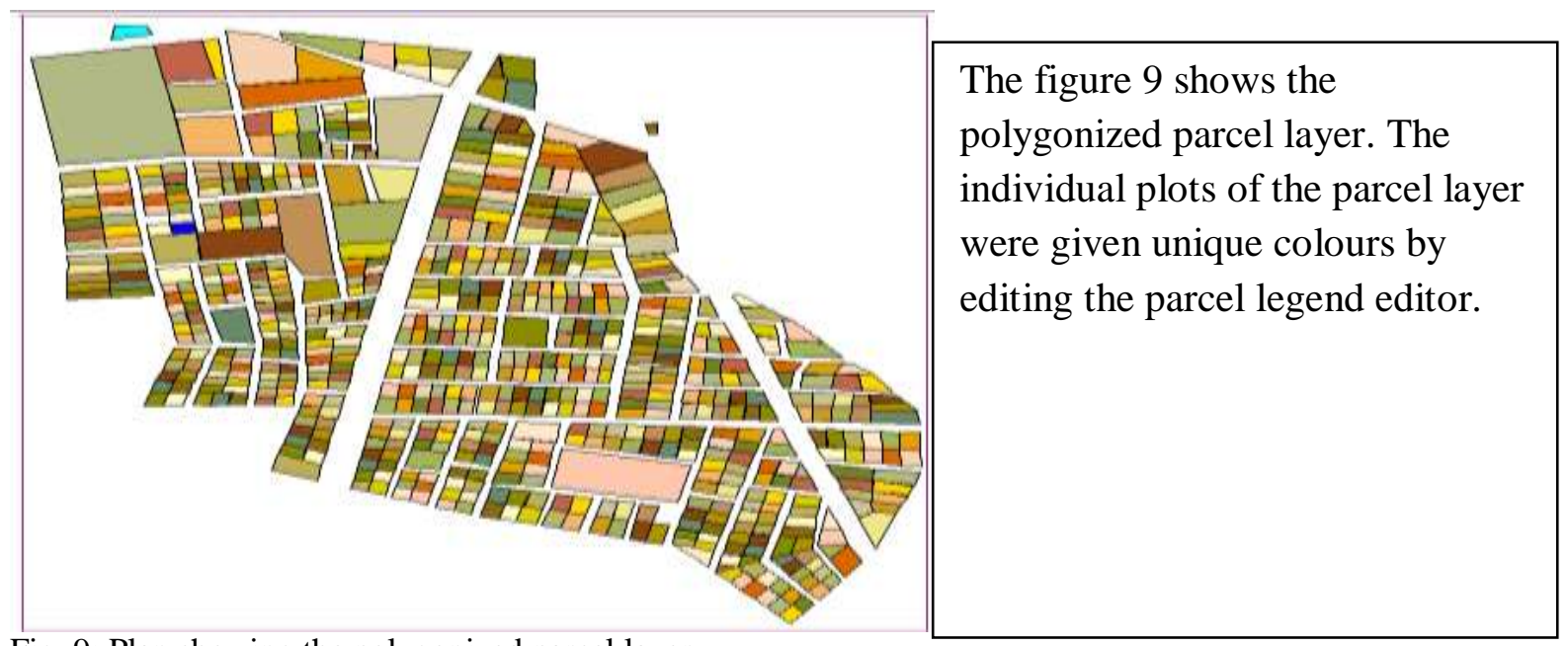

Fig. 9: Plan showing the polygonized parcel layer Table 2:Part of the Parcel Table

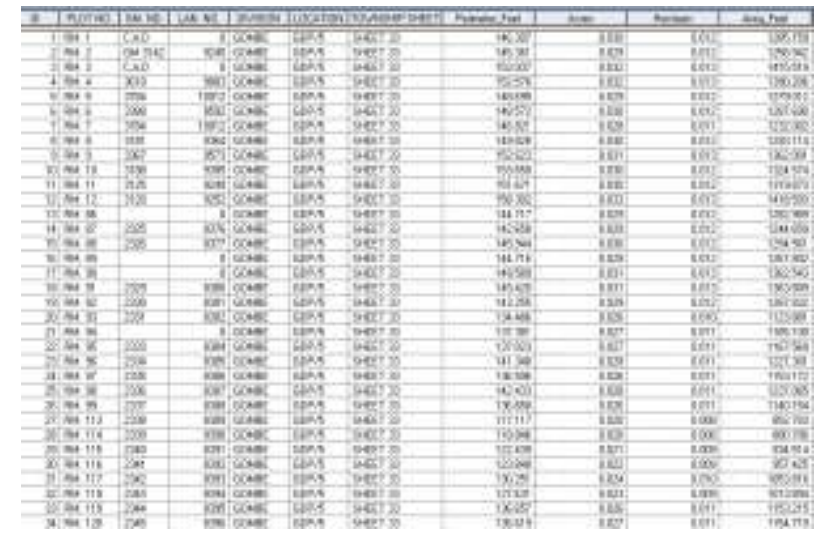

Table 3: Shows Complete Parcel Table with Common Field

(a)




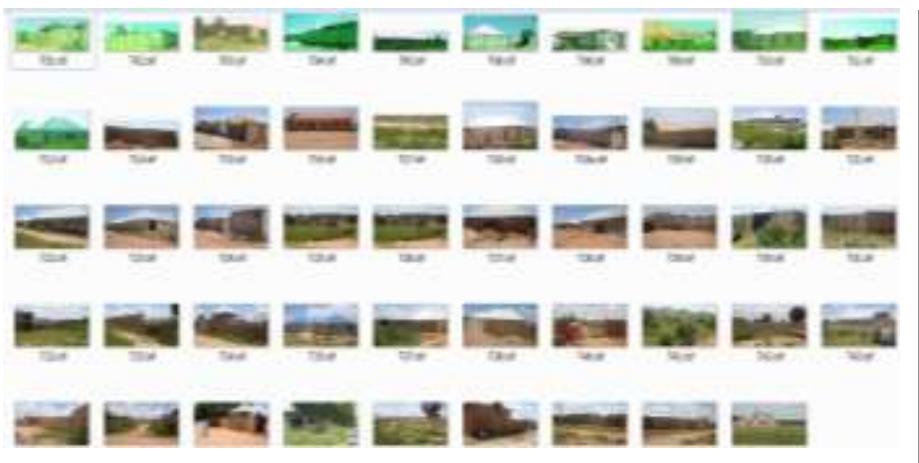

Fig.10: Shows photographs of existing buildings in the area of Study

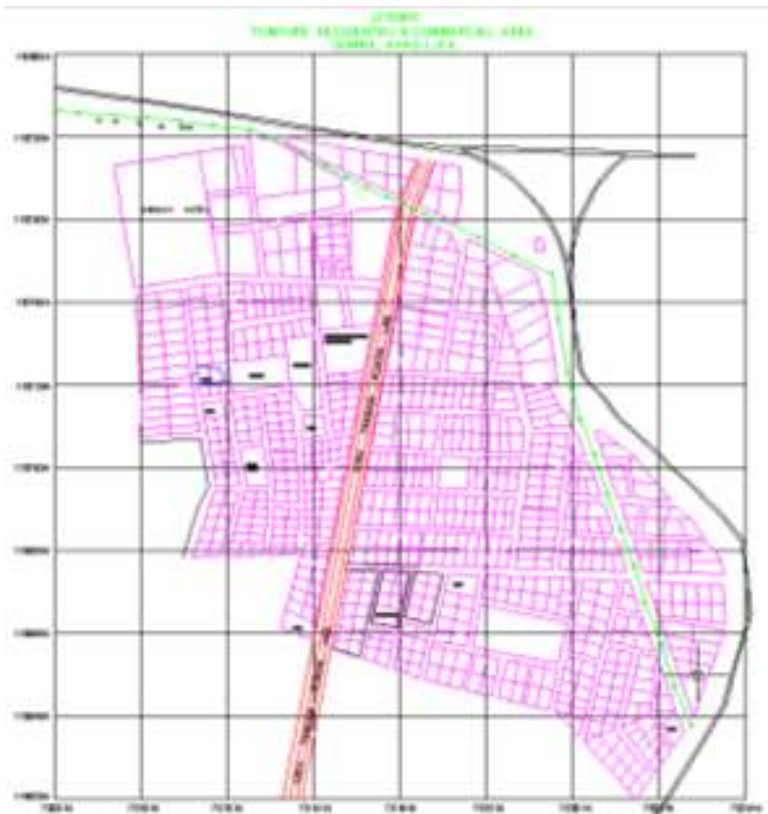

Fig.11: Showing Soft Copy Plan of Tumpure Layout

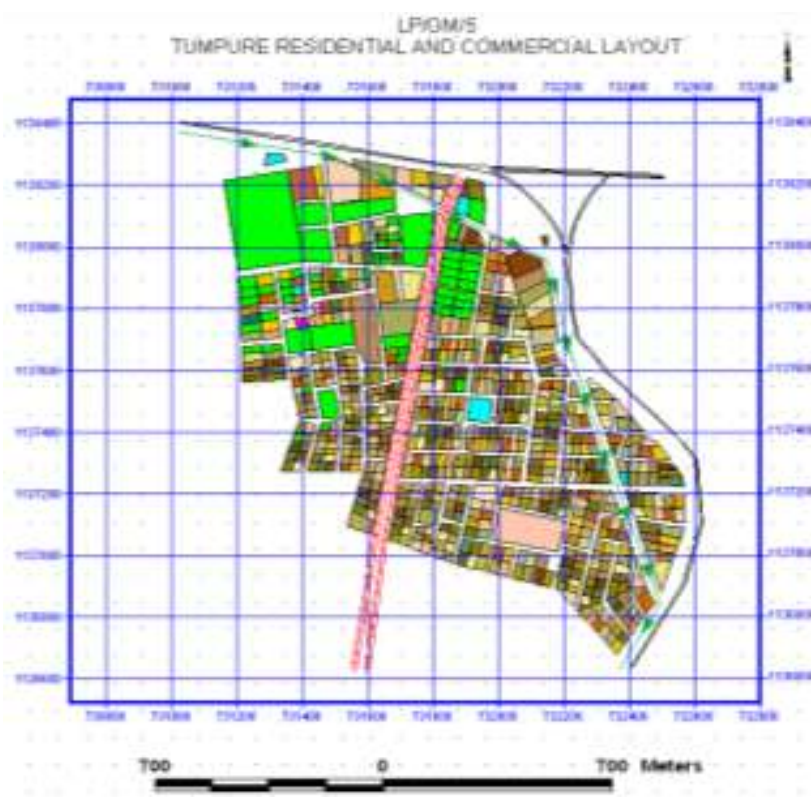

Fig.12: Showing the Composite Plan of Tumpure Layout
The digital photographs of the existing buildings shown in figure 10 were used to relate in each case to the individual parcels concerned. This additional information showing the pictorial characteristics of the parcels now makes the LIS a multimedia scheme.
Figure 12 shows the composite plan of Tumpure layout. The importance of a softcopy plan is numerous, some of are:

It is better than the original copy It is more handy and portable. It occupies less space It allows for unlimited sharing of information.

It avoids the risk of being destroyed by rodents, bad handling or hiding by greedy and selfish individuals and officials etc 


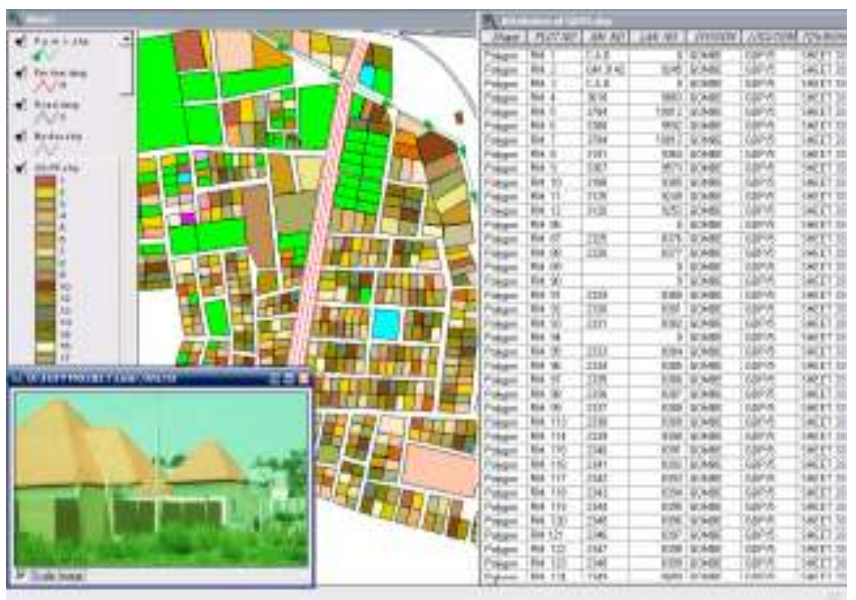

Fig.13: Multimedia Spatial Database of Tumpure Layout

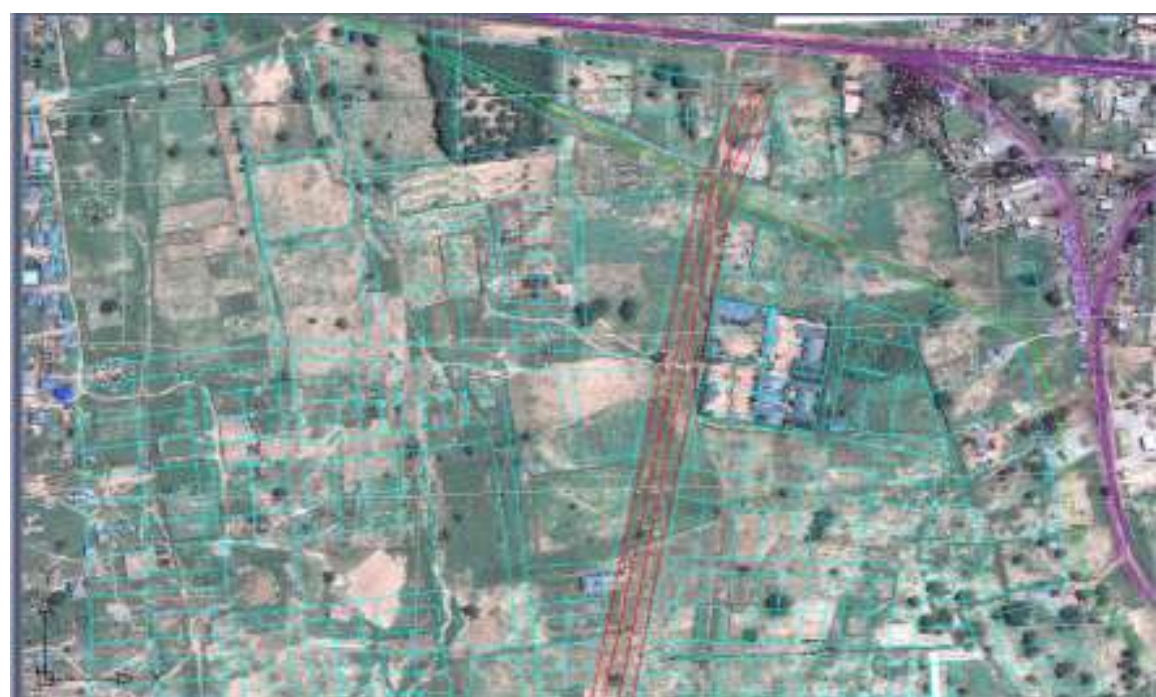

Fig.14: Plan of Overlay of Satellite image with the Layout Plan of Tumpure area

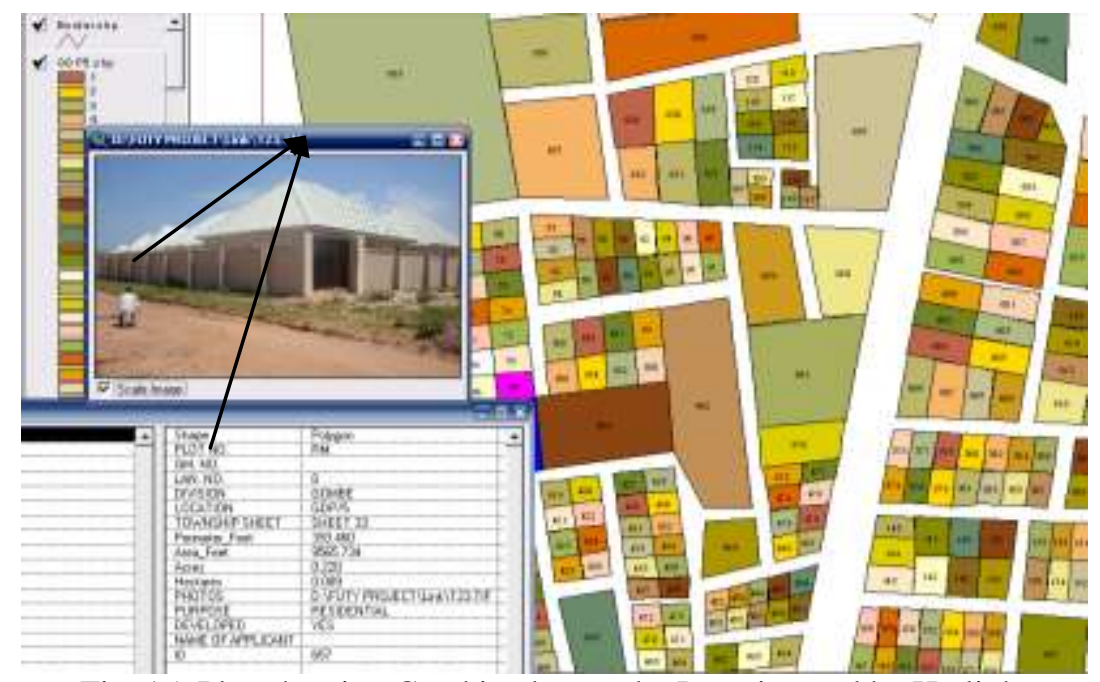

Fig. 15: Plan showing Combined query by Location and by Hotlink. 


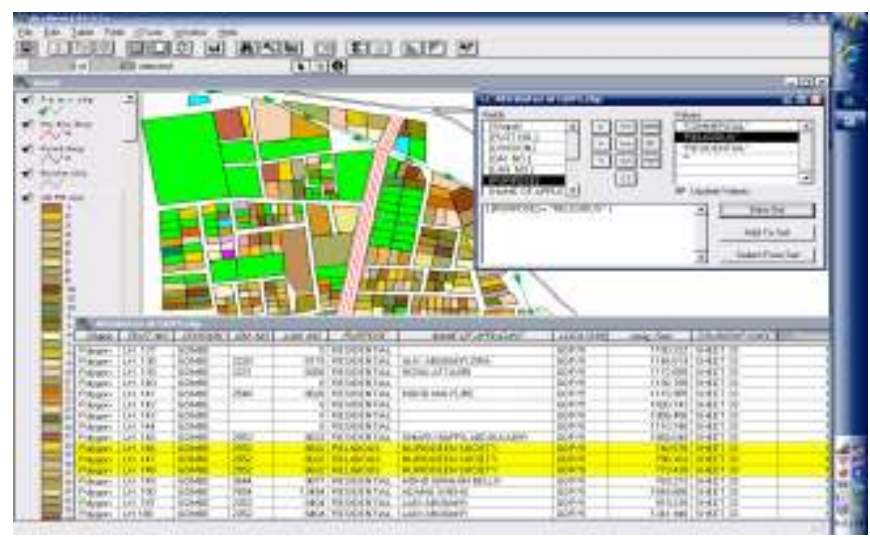

Fig.16: Showing query on all plots allocated for religious purposes

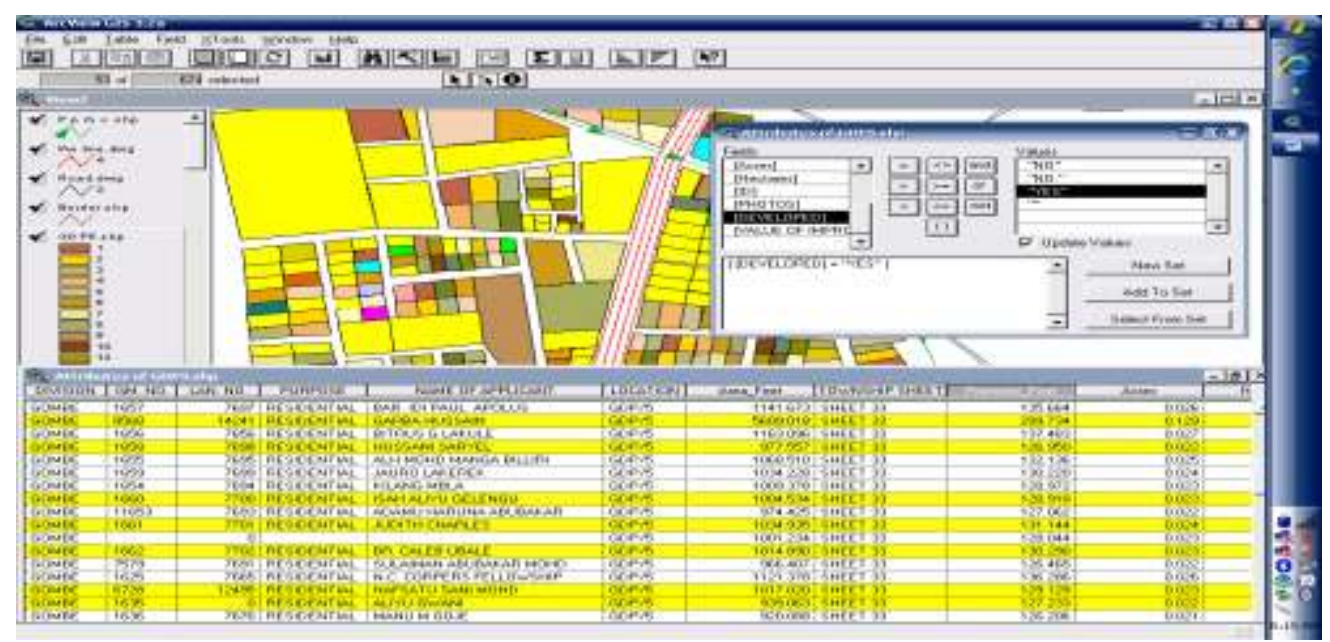

Fig.17: Showing query on all developed plots (In yellow colour)

\section{Conclusion}

The study has provided comprehensive information on Land in Tumpure and presented all information at the parcel level. It is built around a reliable and accurate spatial framework: base maps, a cadastral overlay linked to juridical and fiscal information generated through relevant offices, questionnaires, physical inspections and interviews. Hence it supports both the legal and fiscal purposes.

The study has also shown how computer technology has come to play a vital role in modifying and handling the onetime tedious and cumbersome manual method of land records keeping retrieval. It has also demonstrated the efficiency and efficacy of Land Information System. It is hereby recommended to governments and agencies involved in Land records systems and administration.

\section{References}

[1] Adeoye, A. A. (1996). Geographic Information System. Lagos, Nigeria: Omoniyi Printing Press.

[2] Borma, K., Mesgari, M. S., and, Mansourian, A. (2009, 19th - 22nd October, 2009) Database System for Fiscal Cadastre. Paper presented at the 7th FIG Regional Conference on Spatial Data Serving People, Land Governance and Environment., Honai, Vietnam

[3] Ezeigbo, C. U. (1998). Principles and Applications of Geographic Information Systems. Lagos, Nigeria.: Panaf Press Ltd.

[4] Gabele, F., and, Vanderschueren, M. (2004, 22nd - 27th May). A Better Knowledge for the Partnerns of the Belgian Cadastre. Paper presented at the FIG Working Week, Athens, Greece.

[5] Moha, E. A., Semlali, E. H., Tahiri, D., and, Robert, P. (2003, 2nd - 5th December) New Vision Towards a Multipurpose Cadastral System to Support Land Management in Morocco. Paper presented at the 2nd FIG Regional Conference, Marrakech Ndukwe, N. K. (2001). Digital Technology in Surveying and Mapping. Enugu, Nigeria.: Rhyce Kerex Publishers.

[6] Nieminen, J. (2008, 17th June). Zanzibar Multipurpose Cadastre. Paper presented at the ESRI International User Conference Presentation.

[7] Orisakwe, K. U. (2011). Advanced Land Information Management.Unpublished manuscript, Federal University of Technology, Yola, Nigeria.

[8] Dale, P. F., and, MacLaughlin, J. D. (1988). Land Information Management: An Introduction with Special Reference to Cadastral Problems in Third World Countries. New York: Oxford University Press.

[9] Potdar, V. B. (2010). Land Information System in the Present Day Context. www.GISDevelopment.net.

[10] Shamsul, A. M. (2005). Benefits and Issues of Developing a Multipurpose Cadastre. Unpublished Graduate Students Thesis, University of Melbourne, Australia. 